\title{
Generation of Lyso-Phospholipids from Surfactant in Acute Lung Injury Is Mediated by Type-II Phospholipase A2 and Inhibited by a Direct Surfactant Protein A-Phospholipase A2 Protein Interaction
}

\author{
Laurence Arbibe, ${ }^{*}$ Kamen Koumanov, " Daniel Vial, ${ }^{*}$ Catherine Rougeot, ${ }^{\ddagger}$ Grazyna Faure,, Nathalie Havet, ${ }^{\star}$ Shirley Longacre, ${ }^{\S}$ \\ B. Boris Vargaftig, ${ }^{\star}$ Gilbert Béréziat,,$"$ Dennis R. Voelker, ${ }^{\star *}$ Claude Wolf," and Lhousseine Touqui ${ }^{\star}$ \\ *Unité de Pharmacologie Cellulaire-Unité Associée Pasteur/INSERM U 485, ${ }^{\ddagger}$ Unité de Génétique et de Biochimie du Développement,

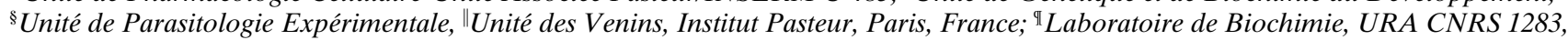 \\ Faculté de Médecine St. Antoine, Paris, France; and the **Department of Medicine, National Jewish Center for Immunology and \\ Respiratory Medicine, Denver, Colorado
}

\begin{abstract}
Lyso-phospholipids exert a major injurious effect on lung cell membranes during Acute Respiratory Distress Syndrome (ARDS), but the mechanisms leading to their in vivo generation are still unknown. Intratracheal administration of LPS to guinea pigs induced the secretion of type II secretory phospholipase A2 (sPLA2-II) accompanied by a marked increase in fatty acid and lyso-phosphatidylcholine (lyso-PC) levels in the bronchoalveolar lavage fluid (BALF). Administration of LY311727, a specific sPLA2-II inhibitor, reduced by $60 \%$ the mass of free fatty acid and lyso-PC content in BALF. Gas chromatography/mass spectrometry analysis revealed that palmitic acid and palmitoyl-2-lysoPC were the predominant lipid derivatives released in BALF. A similar pattern was observed after the intratracheal administration of recombinant guinea pig (r-GP) sPLA2-II and was accompanied by a 50-60\% loss of surfactant phospholipid content, suggesting that surfactant is a major lung target of sPLA2-II. In confirmation, r-GP sPLA2-II was able to hydrolyze surfactant phospholipids in vitro. This hydrolysis was inhibited by surfactant protein A (SP-A) through a direct and selective protein-protein interaction between SP-A and sPLA2-II. Hence, our study reports an in vivo direct causal relationship between sPLA2-II and early surfactant degradation and a new process of regulation for sPLA2-II activity. Anti-sPLA2-II strategy may represent a novel therapeutic approach in lung injury, such as ARDS. (J. Clin. Invest. 1998. 102:1152-1160.) Key words: Acute Respiratory Distress Syndrome • lyso-phospholipids • phospholipase A2 • surfactant • surfactant protein A
\end{abstract}

\section{Introduction}

Pulmonary surfactant is a lipid-protein complex, synthesized by the alveolar type II epithelial cells, that lowers surface ten-

\footnotetext{
Kamen Koumanov and Daniel Vial contributed equally to this work. Address correspondence to Lhousseine Touqui, Unité de Pharmacologie Cellulaire, Unité Associée Institut Pasteur/INSERM U 485, Institut Pasteur, 25 rue Dr. Roux, 75015 Paris, France. Phone: 331-01-40-613-130; FAX: 33-1-01-45-688-703; E-mail: touqui@pasteur.fr

Received for publication 2 March 1998 and accepted in revised form 16 July 1998.
}

J. Clin. Invest.

(C) The American Society for Clinical Investigation, Inc. 0021-9738/98/09/1152/09 \$2.00

Volume 102, Number 6, September 1998, 1152-1160

http://www.jci.org sion along the alveolar epithelium, thereby promoting alveolar stability. Surfactant is composed of $10 \%$ protein and $90 \%$ lipid, with a high proportion of dipalmitoyl-phosphatidylcholine (DPPC). Destruction of surfactant increases surface tension at the air-liquid interface, which results in alveolar collapse, culminating in acute lung injury, such as Acute Respiratory Distress Syndrome (ARDS) (for review see reference 1). Hydrolysis of DPPC is an early physiopathological event that leads to an accumulation of lyso-phosphatidylcholine (lyso-PC) (2). The latter plays a crucial role in acute lung injury since it damages the alveolar type I cellular membranes (3), increases capillary permeability (4), and markedly inactivates the surfactant tensioactivity (5). Furthermore, among lyso-phospholipid subclasses, lyso-PC is the most effective in potentiating the diacylglycerol-induced activation of particular calcium-dependent protein kinase $\mathrm{C}$ isoforms, suggesting a role in cell activation $(6,7)$. Finally, lyso-PC exhibits chemotactic activities toward lymphoid $(8,9)$ and mononuclear cells (10) and induces the expression of vascular cell adhesion molecules and intercellular adhesion molecules in endothelial cells $(11,12)$, suggesting a role in cell recruitment during inflammation.

However, the mechanism(s) leading to the generation of lyso-PC during acute lung injury is still unknown. A key metabolic step in the production of lyso-PC might involve phospholipases A2 (PLA2s). These enzymes hydrolyze the sn-2 fatty acyl ester bond of phosphoglycerides, generating lyso-phospholipids and free fatty acids. Both intracellular and secretory PLA2s (sPLA2s) have been described (13). Among sPLA2s, the $14 \mathrm{kD}$ type II (sPLA2-II) is released in the alveolar space in lung inflammatory processes such as asthma (14) and ARDS (for review see reference 15), but there has never been a demonstration of a direct causal relationship between sPLA2-II expression and the acute generation of lysophospholipids and fatty acids.

Clinical studies in ARDS patients have shown that a destruction of surfactant protein A (SP-A) is associated with a marked increase in lyso-PC content $(1,2)$. SP-A belongs to the $\mathrm{C}$ type lectin superfamily and contains a $\mathrm{COOH}$-terminal carbohydrate recognition domain (CRD) (for review see reference 16). Interestingly, CRD of SP-A shares sequence homol-

1. Abbreviations used in this paper: ARDS, Acute Respiratory Distress Syndrome; AM, alveolar macrophage; BALF, bronchoalveolar lavage fluid; CRD, carbohydrate recognition domain; DPPC, dipalmitoyl-phosphatidylcholine; lyso-PC, lyso-phosphatidylcholine; PLA2, phospholipase A2; sPLA2, secretory PLA2; SP-A, surfactant protein A; SPR, surface plasmon resonance; r-GP sPLA2, recombinant guinea pig sPLA2. 
ogy with a PLA2 inhibitor purified from the plasma of the Habu snake Trimeresurus flavoridis $(17,18)$, suggesting that SP-A might function as a PLA2 inhibitor.

In the context of the above information, we sought to address three questions: Can sPLA2-II account for lyso-PC and fatty acid generation in acute lung injury? Is pulmonary surfactant the target of sPLA2-II during this process? Can SP-A act as a specific inhibitor of sPLA2-II activity?

The present study provides clear evidence that sPLA2-II plays a major role in vivo in the acute generation of lyso-PC during lung injury and that surfactant phospholipids are a major target for this enzyme. Moreover, surface plasmon resonance (SPR) allows us to identify a direct and selective protein-protein interaction between SP-A and sPLA2-II, which plays an important role in the control of sPLA2-II-mediated surfactant phospholipid hydrolysis.

\section{Methods}

\section{Production and purification of the guinea pig type II PLA2}

The recombinant guinea pig (r-GP) sPLA2-II was expressed by using the baculovirus-Sf9 (Spodoptera frujiperda) cell expression system $(19,20)$. Culture medium was centrifuged for $10 \mathrm{~min}$ at $1,500 \mathrm{~g}$ at $4^{\circ} \mathrm{C}$ to remove cells, dialyzed by tangential filtration (Sartocon Micro, $5 \mathrm{kD}$ cut-off; Sartorius, France), and applied to Pep-RPC column, using a fast protein liquid chromatography system (Pharmacia, Uppsala, Sweden). Elution with a linear gradient of $0-100 \%$ acetonitril containing $0.1 \%$ trifluoroacetic acid (TFA) was performed for $60 \mathrm{~min}$ at $1 \mathrm{ml} / \mathrm{min}$ flow rate. After two successive Pep-RPC chromatographies, fractions with PLA2 activity (retention time, 26-28 min) were pooled and applied to a reverse phase Kromasil C18 column (AIT, St. Germain-en Laye, France), using a HPLC system (Spectra-Physics, SP8000). A one-step 40-min linear gradient of 5-100\% acetonitrile containing $0.1 \%$ TFA at $1 \mathrm{ml} / \mathrm{min}$ flow rate was performed.

Purified sPLA2-II fractions (26-27 min retention time or 39-40\% acetonitril) were pooled, lyophilized, and resuspended in $0.01 \%$ TFA solution to measure the activity and protein content. After lyophilization to remove TFA, fractions were dissolved in saline before intratracheal injection. Purified r-GP sPLA2-II gave a single band after tricine SDS-PAGE (21) and silver staining (Fig. $1 B$ ). An equal volume of $40 \%$ acetonitrile solution was treated exactly like the pooled purified protein fractions and used as control solvent for the in vivo experiments.

\section{Purification of guinea pig SP-A}

A purified surfactant fraction was isolated by $\mathrm{NaCl}-\mathrm{NaBr}$ gradient centrifugation (22). Guinea pig SP-A was extracted from purified surfactant using 1-butanol and octyl- $\beta$-D-glucopyranoside, as described (23). Delipidation of the protein was checked by measuring the phosphorus content as described by Böttcher et al. (24). Analysis on $12 \%$ PAGE under nonreducing conditions showed that the major form had a molecular mass of $66 \mathrm{kD}$, sharing the same mobility as purified rat SP-A. Purified guinea pig SP-A reacted positively with a polyclonal rabbit anti-rat SP-A (23) by Western blot analysis (data not shown).

\section{In vivo experiments}

Male Hartley guinea pigs (elevages; Saint Antoine, Pleudaniel, France) weighing 400-600 g were anesthetized by the intramuscular injection of ketamine hydrochloride $(50 \mathrm{mg} / \mathrm{kg}$ of body weight; ParkeDavis, Courbevoie, France) and xylazine $(2 \mathrm{mg} / \mathrm{kg}$ body weight; Bayer, Leverkusen, Germany). Three sets of experimental protocols were performed.

LPS challenge. After orotracheal intubation, either $330 \mu \mathrm{g} / \mathrm{kg}$ of LPS from Escherichia coli 055:B5 (DIFCO Laboratories, Detroit, MI) in $300 \mu \mathrm{l}$ of $0.9 \% \mathrm{NaCl}$ (saline) or the same volume of saline

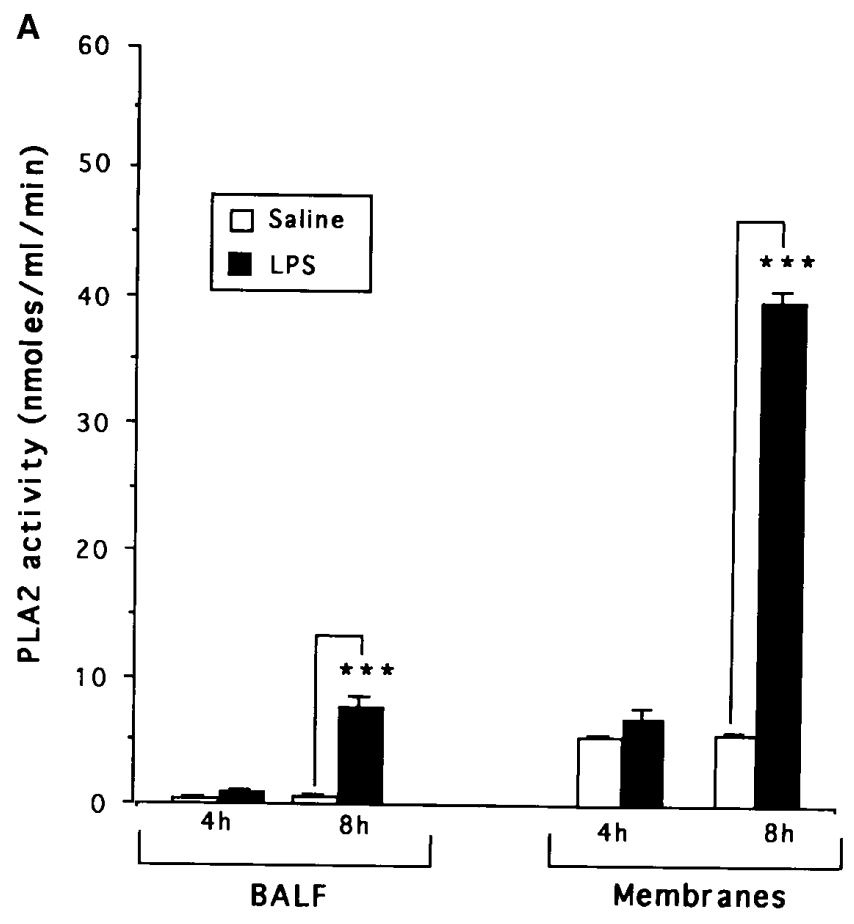

B
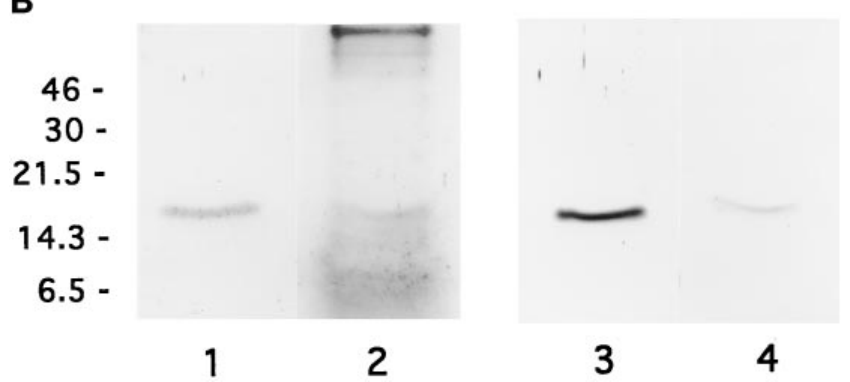

Figure 1. Analysis of sPLA2-II expression in BALF and lung tissues after intratracheal LPS administration. In $(A)$, sPLA2 activities in lung membranes and BALF from saline or LPS-treated guinea pigs were measured as indicated in Methods. The data are expressed as means \pm SE, $n=5$, **P $P$ 0.001. In $(B)$, LPS-induced sPLA2 activity was characterized from BALF after one-step purification by HPLC as indicated in Methods. Analysis by SDS-PAGE of the 39\% acetonitrile HPLC fraction (100 ng) shows a band at $16 \mathrm{kD}$ (lane 2) with the same mobility as r-GP sPLA2-II (500 ng) (lane 1). Corresponding immunoblots were probed with rabbit polyclonal anti-sPLA2-II (lane 3, r-GP sPLA2-II; lane 4,39\% acetonitrile HPLC fraction obtained from BALF). The pattern is representative of three separate experiments.

alone was instilled through an intratracheal catheter (see reference 25). This experimental model of acute lung injury was previously shown to reproduce the main characteristic of ARDS at the early phase of disease (25). $8 \mathrm{~h}$ after instillation, animals were killed with an overdose of pentobarbital sodium $(40 \mathrm{mg} / \mathrm{kg}$; Sanofi, Libourne, France).

LY311727 treatment. The animals were assigned to three experimental groups. The first group received intravenous injections of LY311727 (3-acetamine-1-benzyl-2-ethylindolyl-5-oxy; propane phosphonic acid; Eli Lilly, Indianapolis, IN), $2 \mathrm{mg} / \mathrm{kg}$ of body weight dissolved in $25 \mu \mathrm{l}$ of DMSO (26), $24 \mathrm{~h}$ and $1 \mathrm{~h}$ before LPS administration. A third injection of LY311727 (2 mg/ $/ \mathrm{kg}$ of body weight dissolved in $25 \mu \mathrm{l}$ of DMSO) was administrated intratracheally with LPS 
(330 $\mu \mathrm{g} / \mathrm{kg}$, dissolved in $275 \mu \mathrm{l}$ of saline). The two other groups received two intravenous injections of DMSO alone at the time indicated above and were then injected intratracheally with the same volume of DMSO plus either $330 \mu \mathrm{g} / \mathrm{kg}$ LPS or saline. $8 \mathrm{~h}$ after the challenge, the animals were killed.

Recombinant guinea pig sPLA2-II challenge. r-GP sPLA2-II and its control solvent were prepared as indicated above and resuspended in saline. After orotracheal intubations, guinea pigs received either $250 \mu \mathrm{g}$ of r-GP sPLA2-II or its solvent dissolved in $300 \mu \mathrm{l}$ of saline. The animals were killed $2 \mathrm{~h}$ after the challenge. Preliminary experiments allowed us to determine that a dose of $250 \mu \mathrm{g}$ of r-GP sPLA2II corresponds to the concentration of endogenous sPLA2-II produced by the lung upon LPS challenge. Indeed, after the intratracheal administration of $250 \mu \mathrm{g}$ of r-GP sPLA2-II, the levels of sPLA2 activity recovered from the bronchoalveolar lavage fluid (BALF) were comparable to those detected after LPS administration $(17 \pm 7 \mathrm{nmol} /$ $\mathrm{ml} / \mathrm{min}$ vs. $10 \pm 1 \mathrm{nmol} / \mathrm{ml} / \mathrm{min}, n=4$, respectively).

Preparation of bronchoalveolar lavage and lung homogenates

At the indicated times, bronchoalveolar lavages were performed as previously described (25) and immediately stored at $-20^{\circ} \mathrm{C}$ for subsequent analysis. Lungs were rapidly excised, frozen in liquid nitrogen, and stored at $-80^{\circ} \mathrm{C}$ until use. Lung homogenates were prepared as described by Filgueiras and Possmayer (27), and then membrane and cytosolic fractions were used for the determination of sPLA2 activity.

\section{Isolation and incubation of pulmonary surfactant}

Crude surfactant was obtained by 20-min centrifugation at 19,500 $\mathrm{g}$ of cell-free BALFs from naive animals, resuspended in Hank's buffer, and then submitted to $5 \mathrm{~min}$ of ultrasonication $(150 \mathrm{~W})$ using a MSE sonifer. After adjusting the phospholipid concentration to $4 \mathrm{mM}$ (which corresponded to the $\mathrm{V}_{\max }$ of the enzyme), surfactant was incubated for $2 \mathrm{~h}$ at $37^{\circ} \mathrm{C}$ with the indicated r-GP sPLA2-II concentrations, in the presence of $5 \mathrm{mM} \mathrm{Ca}^{2+}$. This concentration was effective in lowering surface tension (5).

To analyze the consequence of SP-A/sPLA2-II interaction on phospholipid hydrolysis by r-GP sPLA2-II, a surfactant preparation ( $4 \mathrm{mM}$ phospholipid concentration, containing $600 \mu \mathrm{g} / \mathrm{ml}$ total proteins) was preincubated with $5.2 \mu \mathrm{g}$ of anti-rat SP-A IgG or normal rabbit $\mathrm{IgG}$, in a final volume of $50 \mu \mathrm{l}$, overnight at room temperature. Surfactant was then incubated for $2 \mathrm{~h}$ at $37^{\circ} \mathrm{C}$ with $150 \mathrm{ng} / \mathrm{ml} \mathrm{r}-\mathrm{GP}$ sPLA2-II, and fatty acid release was analyzed as described below.

\section{Phospholipid analysis}

Lipids were extracted from BALF or from isolated surfactant according to Bligh and Dyer (28). The separation of phospholipids was achieved on thin-layer chromatography on silicagel (Merck, St. Louis, MO) with water/acetic acid/methanol/chloroform (65:45:3:1, vol/vol) solvent system. The phosphorus content of phospholipids was determined according to Böttcher et al. (24). To analyze the $s n-1$ fatty acid composition of lyso-PC, the corresponding spot was saponified with $0.5 \mathrm{~N}$ methanolic $\mathrm{KOH}$ and methylated with boron trifluoride in $14 \%$ methanol. The resulting fatty acid methyl esters were analyzed as indicated below.

\section{Analysis of fatty acids by gas chromatography/mass spectrometry}

Fatty acids were extracted by Dole's procedure modified by Tsujishita et al. (29) and methylated with diazomethane. The methylated derivatives were separated by GC on a capillary column containing Supelcowax 10 bonded phase (diameter $0.32 \mathrm{~mm}, 30 \mathrm{~m}$ long; Supelco Inc., Bellefonte, PA) on a gas chromatograph (5890 Series II; Hewlett-Packard, Palo Alto, CA) and detected by MP (Nermag 1010C, France).

\section{Isolation and analysis of SPLA2-II from BALF}

BALF samples collected from four LPS-challenged animals were dialyzed by tangential filtration, lyophilized, and applied to HPLC as described above. Fractions $(1 \mathrm{ml})$ were collected and aliquots were as- sayed for sPLA2 activity. Further characterization was performed by Western blot analysis. Antiserum was raised in rabbits immunized against the peptide "YDRLMKRGCGTKFL" conjugated to sunflower globulin using the bis-diazoted benzidine (30). This peptide, corresponding to 51-64 amino acids of the mature guinea pig sPLA2II protein (31), is not present in other known secreted PLA2s.

After Tricine SDS-PAGE, r-GP sPLA2-II, and BALF samples were transferred to nitrocellulose membranes (CERA-LABO, France) and probed with the globulin fraction of antiserum. Bands were visualized by the use of alkaline phosphatase-conjugated antirabbit IgG (Promega, Madison, WI), followed by BCIP/NBT substrates (Sigma, France).

\section{Characterization of $S P L A 2-I I / S P-A$ protein interaction using $S P R$}

Studies were performed using a BIAcore 2000 apparatus (Pharmacia Biacore). Sensor chips CM5, surfactant P20, the amine coupling kit containing $N$-hydroxysuccinimide (NHS), $N$-ethyl- $N^{\prime}$-(3-diethylaminopropyl)carbodiimide (EDC), and ethanolamine hydrochloride were obtained from Pharmacia Biacore. The running buffer used for all experiments was $5 \mathrm{mM}$ Hepes (pH 7.4), 0.005\% surfactant P20.

The Biacore instrument is a biosensor-based system for real-time biospecific interaction analysis. Biosensor technology is based on optical SPR and detects small changes in the refraction index on the surface of a thin gold film. The latter is coated with a dextran matrix to which one of the reactants (sPLA2) is covalently linked, while the other one (SP-A) is introduced into a flow passing over the surface. The resonance angle, expressed in resonance units (RUs), depends on the refraction index of the vicinity of the surface and changes with the concentration of molecules on the surface (32).

Immobilization of proteins on the sensor surface. r-GP sPLA2-II was covalently coupled via primary amino groups on a CM5-sensor chip surface according to the manufacturer's specifications. The immobilization run was performed at a flow of $5 \mu \mathrm{l} / \mathrm{min}$ at $25^{\circ} \mathrm{C}$. Briefly, after equilibration of the dextran with the running buffer, the carboxymethylated matrix was activated with an EDC/NHS mixture, 10 $\mu \mathrm{l}$ of $\mathrm{r}$-GP sPLA2-II $(20 \mu \mathrm{g} / \mathrm{ml})$ in $10 \mathrm{mM}$ sodium acetate $(\mathrm{pH} 4.8)$ was injected, and unreacted groups were blocked by the injection of ethanolamine ( $\mathrm{pH} 8.5)$, followed by $5 \mu$ of $50 \mathrm{mM}$ Glycine/ $\mathrm{HCl}(\mathrm{pH}$ 2.0) to remove noncovalently bound protein. A sensor chip was also subjected to a blank immobilization on independent flow cells. The immobilization of other PLA2s was performed using the same protocol. The SPR signals for immobilized proteins were, respectively, 3264 RUs for r-GP sPLA2-II, 3787 RUs for bee venom sPLA2-III (a gift of Dr. G. Lambeau, Sophia Antipolis, France), 3440 RUs for synovial human sPLA2-II (a gift of Dr. J.L. Browning, Biogen, Cambridge, MA), 5500 RUs for sPLA2-II purified from Crotallus durissus terrificus venom (33), 1341 RUs for Naja-Naja sPLA2-I (Sigma), and 7164 RUs for porcine pancreatic sPLA2-I (a gift of Dr. B. Verheij, Utrecht University, The Netherlands).

Analysis of protein-protein interaction. The association of SP-A to immobilized sPLA2s was studied by injecting at $25^{\circ} \mathrm{C}, 10-20 \mu \mathrm{g} / \mathrm{ml}$ SP-A in $5 \mathrm{mM}$ Hepes (pH 7.4), with $5 \mathrm{mM} \mathrm{Ca}^{2+}$ at a flow rate of 10 $\mu 1 /$ min. Dissociation of SP-A from sPLA2s was performed by an injection of $5 \mathrm{mM}$ Hepes ( $\mathrm{pH}$ 7.4) without cation. The analysis was carried out using the BIAevaluation software (Pharmacia Biacore). For experiments using rabbit anti-SP-A IgG, SP-A $(10 \mu \mathrm{g} / \mathrm{ml})$ was preincubated in a volume of $100 \mu \mathrm{l}$ with anti-SP-A IgG $(10 \mu \mathrm{g} / \mathrm{ml})$ or normal rabbit IgG for $6 \mathrm{~h}$, and then injected in the same buffer in the presence of $\mathrm{Ca}^{2+}$ (the SP-A/anti-SPA IgG ratio was 1:40) assuming a $650 \mathrm{kD}$ octadecameric form of SP-A in low ionic strength buffer (34).

\section{Measurement of PLA2 activity}

The measurement of sPLA2 activity was carried out using the fluorimetric assay, as described by Radvanyi et al. (35) using 1-hexadecanoyl-2-(1-pyrenedecanoyl)-sn-glycero-3-phosphoglycerol [PG]; Interchim, Montluçon, France) as substrate. The enzymatic reaction was initiated by the addition of $10 \mathrm{mM}$ calcium. The calcium-independent 
Table I. Effect of SP-A on the Enzymatic Activity of $r$-GP sPLA2-II and Porcine Pancreatic sPLA2

\begin{tabular}{cccc}
\hline & & \multicolumn{2}{c}{ sPLA2 activity } \\
\cline { 3 - 4 } sPLA2 type & SP-A/sPLA2 ratio & $\mathrm{nmol} / \mathrm{ml} / \mathrm{min}$ & Percent control \\
\hline r-GP-sPLA2-II & 0 & $20.9 \pm 0.5$ & 100 \\
& 0.5 & $21.5 \pm 0.5$ & 102 \\
Pancreatic sPLA2 & 1 & $12.7 \pm 1.5$ & 60 \\
& 2 & $4.6 \pm 0.2$ & 22 \\
& 0 & $22.5 \pm 0.6$ & 100 \\
& 2 & $21.5 \pm 0.7$ & 94
\end{tabular}

Fixed concentration (714 nM) of sPLA2 (r-GP sPLA2-II or pancreatic sPLA2) was incubated with various concentrations of SP-A at the indicated molar ratio. Incubations were carried out for $1 \mathrm{~h}$ at $37^{\circ} \mathrm{C}$ in phospholipid-free Tris buffer $(50 \mathrm{mM})$ in the presence of $5 \mathrm{mM}$ calcium (solution A). After $1 / 20$ dilution, $5 \mu \mathrm{l}$ from solution A was introduced into a cuvette containing $1 \mathrm{ml}$ of the fluorescent phospholipid PG $(2 \mu \mathrm{M})$, then SPLA2 activity was measured as described in Methods. Each point is the mean $\pm \mathrm{SE}$ of two separate experiments carried out in triplicate.

PLA2 activity was measured by using 1-palmitoyl-2-(1-pyrenedecanoyl)-sn-glycero-3-phosphocholine (Interchim) as substrate, in the presence of EGTA $(10 \mathrm{mM})$.

To analyze the effect of SP-A on SPLA2 activity, a fixed concentration $(714 \mathrm{nM}$ ) of sPLA2 (pancreatic sPLA2 or r-GP sPLA2-II) was incubated with various concentrations of SP-A at the molar ratios indicated in Table I. Incubations were carried out for $1 \mathrm{~h}$ at $37^{\circ} \mathrm{C}$ in Tris buffer $(50 \mathrm{mM})$ in the presence of $5 \mathrm{mM} \mathrm{Ca}^{2+}$ (solution A). After 1/20 dilution, $5 \mu \mathrm{l}$ from solution A was introduced into the cuvette containing $1 \mathrm{ml}$ of the fluorescent phospholipid PG $(2 \mu \mathrm{M})$, for the measurement of sPLA2 activity, leading to a dilution factor of 4,000 of the starting material. At the molar ratio of 1:1 between SP-A and sPLA2, the final calculated concentration of SP-A in the cuvette was near 0.2 $\mathrm{nM}$, leading to a 10,000 -fold molar excess of phospholipid substrate $\mathrm{PG}$, as compared with SP-A.

\section{Calculations and statistical analyses}

The data (expressed as mean $\pm \mathrm{SE}$ of separate experiments) were initially subjected to factorial ANOVA, and statistical analyses were performed using Student's $t$ test for unpaired values. A value of $P \leq$ 0.05 was considered significant.

\section{Results}

Involvement of SPLA2-II in the in vivo generation of lyso-PC and fatty acids. We have previously shown that intratracheal administration of LPS to guinea pig stimulates the synthesis of sPLA2-II in lung tissues through the activation of sPLA2-II gene expression (25). Here we investigated the time course of sPLA2-II appearance in lung tissues and BALF and its relationship with fatty acid and lysophospholipid generation. No induction of sPLA2 activity was detected $4 \mathrm{~h}$ after the intratracheal injection of LPS, whereas a marked increase was observed in BALF and lung membranes after $8 \mathrm{~h}$ (Fig. $1 A$ ). We next characterized the sPLA2 recovered in BALF after in vivo LPS administration. Each fraction collected after a Pep-RPC chromatography was assayed for sPLA2 activity. We essentially detected a sPLA 2 activity in the fraction that coeluted at the same retention time $(26-27 \mathrm{~min})$ as recombinant guinea pig sPLA2-II (r-GP sPLA2-II) (data not shown).
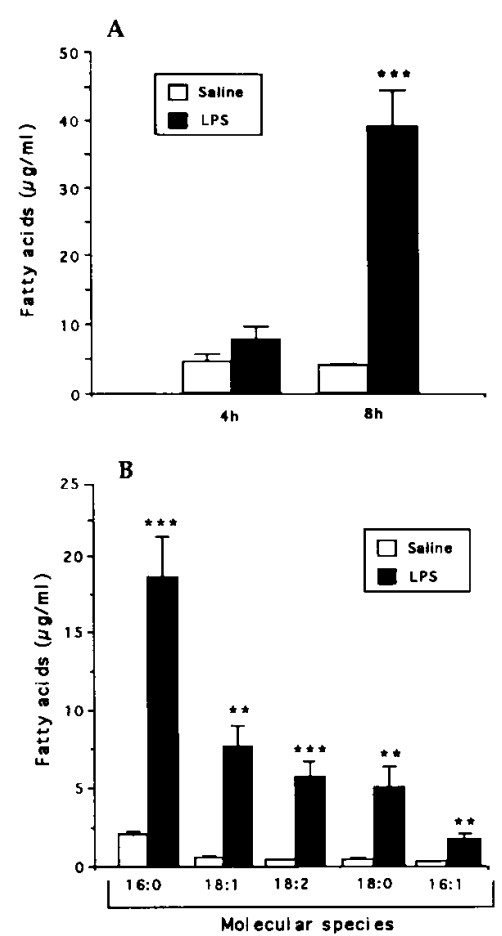

Figure 2. GC/MS analysis of fatty acids and lyso-PC levels in BALF after intratracheal administration of LPS. The animals were treated with saline or LPS instillation as indicated in Methods. In $(A)$, the fatty acid generation in BALF was measured at $4 \mathrm{~h}(n=4)$ and $8 \mathrm{~h}(n=8)$ after the

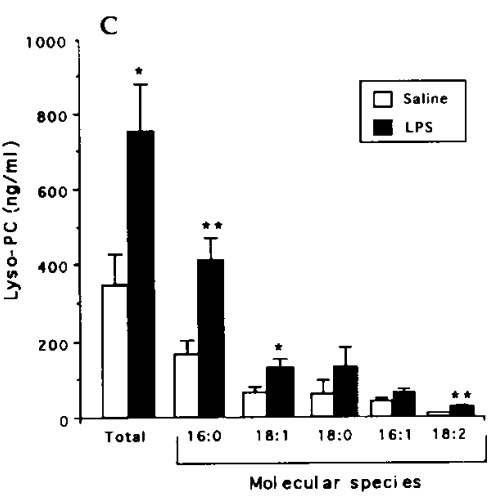
challenge. $(B)$ shows the molecular species of the fatty acids released; $(C)$ shows the molecular species of lyso-PC released in BALF, $8 \mathrm{~h}$ after the challenge $(n=8)$. The data are expressed as means \pm SE; $* P<0.05$, $* * P<0.01$, and $* * * P<$ 0.001 , as compared to saline-challenged animals.

Analysis by SDS-PAGE of this fraction showed a band at $16 \mathrm{kD}$ sharing the same electrophoretic mobility as r-GP sPLA2-II (Fig. $1 B$, lanes 1 and 2 ) and which was selectively recognized by the rabbit anti-sPLA2-II antibody (Fig. $1 B$, lanes 3 and 4).

A tenfold increase of fatty acid levels was observed $8 \mathrm{~h}$ after LPS challenge (Fig. 2 A). Gas chromatography/mass spectrometry (GC/MS) analysis showed that palmitic acid (C16:0) was the major fatty acid released in the BALF (Fig. $2 \mathrm{~B}$ ). This was accompanied by a twofold increase in the level of lyso-PC released in BALF, mostly attributed to 1-palmitoyl-2-lyso-PC (Fig. 2 C). However, the levels of arachidonic acid (C20:4) were very low and remained unchanged after LPS challenge ( $30 \pm 3$ vs. $24 \pm 6 \mathrm{ng} / \mathrm{ml}$; mean $\pm \mathrm{SE}, n=6$, in control and LPStreated animals, respectively).

To analyze the causal relationship between the induction of sPLA2-II and the generation of the lipid derivatives, similar experiments were performed following in vivo administration of a specific sPLA2-II inhibitor, LY311727 (26). This compound inhibited over $80 \%$ of the LPS-induced sPLA 2 activity recovered in BALF from LPS-challenged animals (Fig. $3 A$ ). 


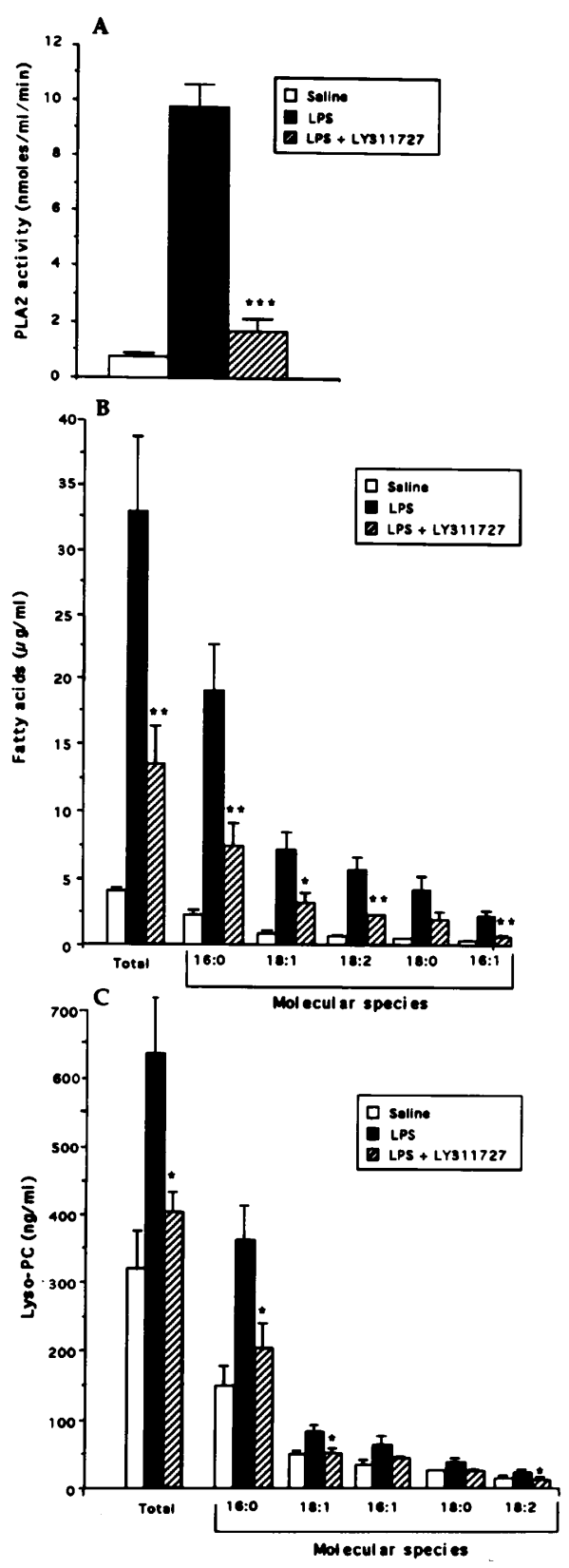

Figure 3. Effect of in vivo administration of LY311727 on sPLA2 activity and the levels of fatty acids and lyso-PC in BALF. The animals were treated with saline, LPS plus vehicle, or LPS plus LY311727 as indicated in Methods. BALF analyses were performed $8 \mathrm{~h}$ after intratracheal instillation. The results show sPLA2 activity $(A)$ and fatty acid levels $(B)$ in BALF from saline $(n=6)$, LPS plus vehicle $(n=15)$, or LPS plus LY311727 $(n=11)$. (C) shows lyso-PC levels in BALF after administration of saline $(n=6)$, LPS plus vehicle $(n=$ $6)$, or LPS plus LY311727 $(n=6)$. The data are expressed as means \pm SE, $* P<0.05$, $* * P<0.01$, and $* * * P<0.001$, as compared with LPS-treated group.

A calcium-independent PLA2 activity was detected in lung homogenates from LPS-treated animals. This activity remained unchanged when homogenates were incubated for $10 \mathrm{~min}$ with $25 \mu \mathrm{M}$ of LY311727 $(0.88 \pm 0.18$ and $1.04 \pm 0.22 \mathrm{nmol} / \mathrm{ml} / \mathrm{min}$, in control and LY311727-treated homogenates, respectively, $n=$ 6). At this concentration, LY311727 markedly reduced sPLA2-
II activity in guinea pig lung (25). This was accompanied by a reduction of $60 \%$ in the mass of free fatty acids in BALF and by a similar reduction in the palmitic acid content (Fig. $3 \mathrm{~B}$ ). A parallel decrease in the content of lyso-PC, mainly the 1-palmitoyl-2-lyso-PC level, was observed (Fig. $3 C$ ).

To confirm these results, administration of exogenous recombinant GP sPLA2-II (r-GP sPLA2-II) induced an increase in the levels of lyso-PC, essentially composed by 1-palmitoyl-2 lyso PC (Fig. 4). This was accompanied by a 2.4 -fold increase in the concentration of fatty acids in the BALF (5.0 $\pm 0.1 \mathrm{vs}$. $12.0 \pm 1.4 \mu \mathrm{g} / \mathrm{ml}$, in control and r-GP sPLA2-II-treated animals, respectively; $P<0.001 ; n=4-8$ ), mainly composed by palmitic and oleic acids.

Hence, our results show that sPLA2-II is involved in the generation of lyso-PC and fatty acids during LPS-induced acute lung injury and that palmitic acid and 1-palmitoyl 2-lyso$\mathrm{PC}$ are the main components released during this process. Since DPPC is the major phospholipid of mammalian surfactant (36), our findings suggest that the latter is a likely target for sPLA2-II during LPS-induced acute lung injury.

Involvement of SPLA2-II in the hydrolysis of surfactant phospholipids. Intratracheal administration of LPS led to a marked loss in the phospholipid content of total crude surfactant $(4.2 \pm 0.7 \mathrm{mg}$ vs. $2.1 \pm 0.2 \mathrm{mg}$, in control and LPS-treated animals, respectively, $P<0.01 ; n=9$ ), associated to an increase in the lyso-PC content (1-palmitoyl-2-lyso-PC being the predominant molecular species) (Fig. $5 \mathrm{~A}$ ). Identically, in-

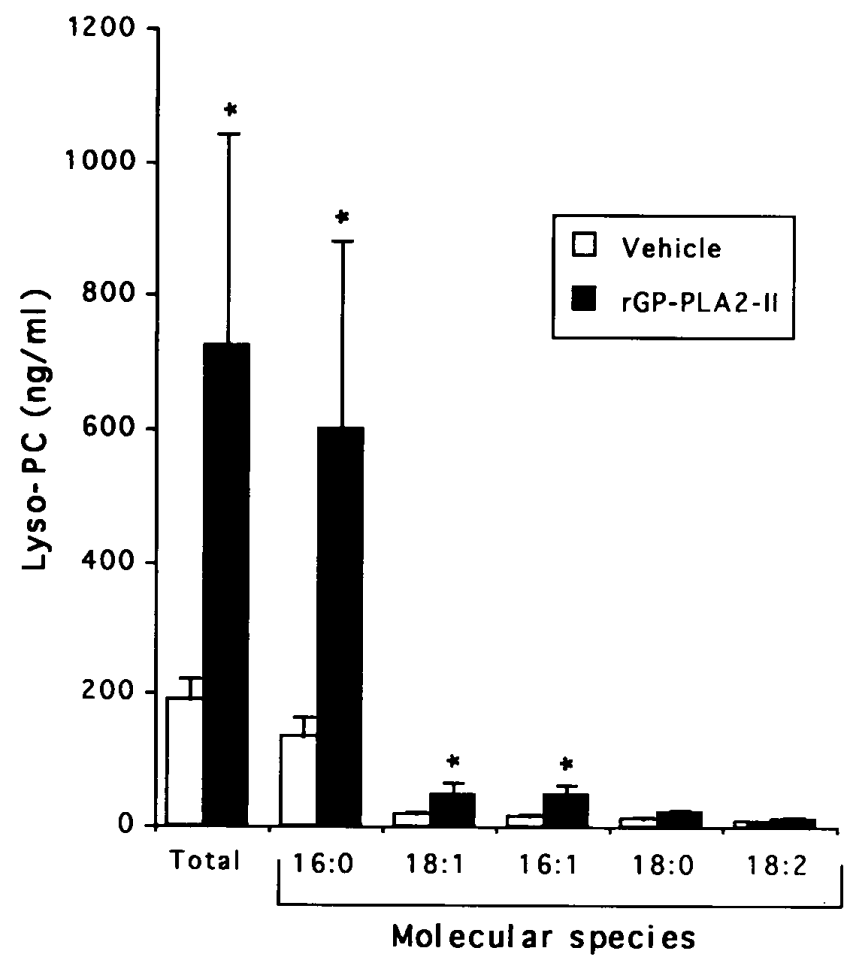

Figure 4. Effect of intratracheal administration of r-GP sPLA2-II on lyso-PC release in BALF. BALF analyses were performed $2 \mathrm{~h}$ after intratracheal instillation of vehicle $(n=8)$ or $250 \mu \mathrm{g}$ of r-GP sPLA2II $(n=4)$. Lipids were extracted from BALF and lyso-PC isolated by TLC. Lyso-PC molecular species were analyzed by GC/MS. The data are expressed as means $\pm \mathrm{SE}, * P<0.05$, as compared with vehiclechallenged guinea pigs. 
A
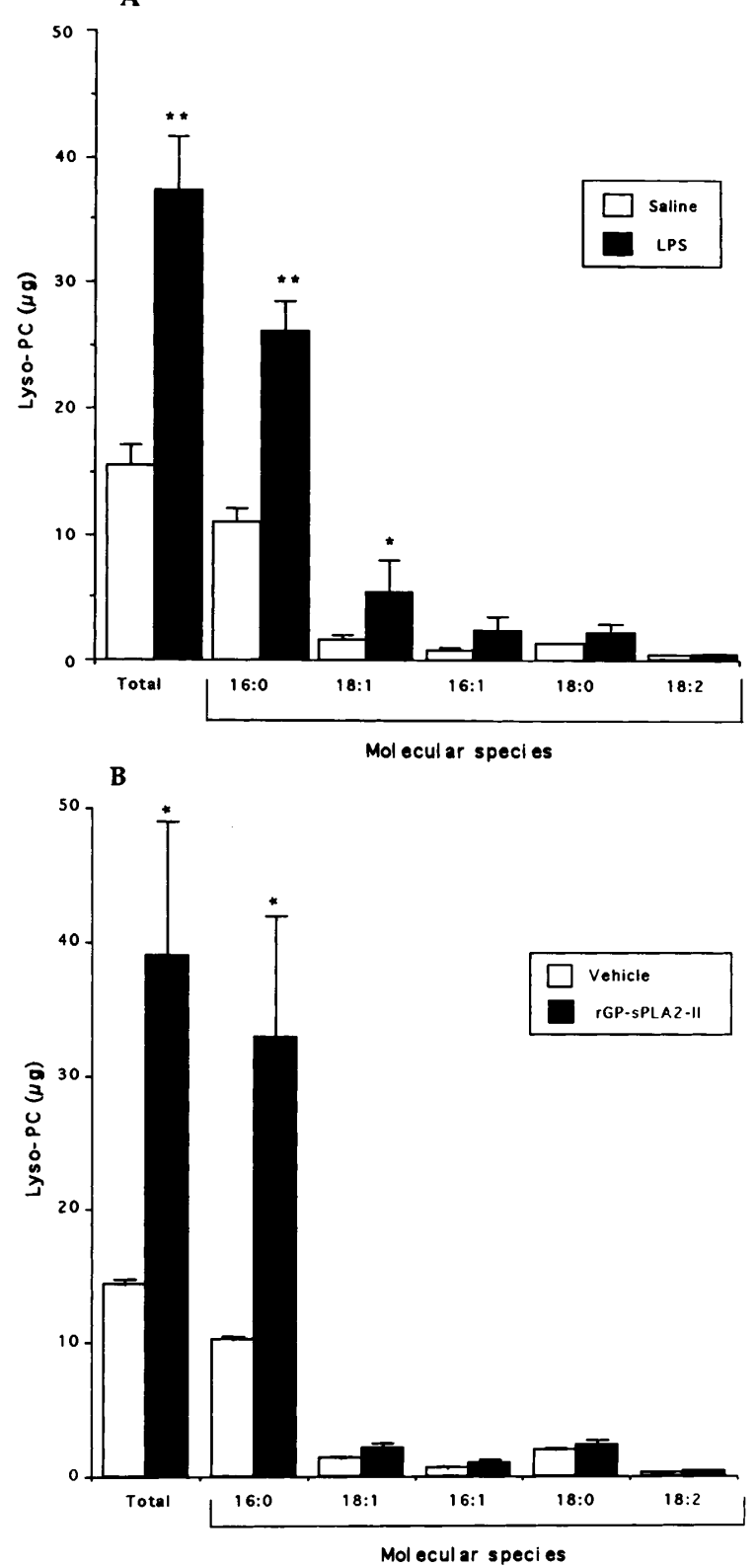

Figure 5. Determination of lyso-PC content in the crude surfactant pellet after intratracheal administration of LPS and r-GP sPLA2-II. The animals were instilled intratracheally with LPS or r-GP-sPLA2II or corresponding vehicles. The crude surfactants were collected and lyso-PC analyzed as detailed in Methods. In $(A)$, surfactant was isolated $8 \mathrm{~h}$ after LPS or saline challenges $(n=9)$. In $(B)$, surfactant was collected $2 \mathrm{~h}$ after administration of $250 \mu \mathrm{g}$ of r-GP sPLA2-II or its vehicle $(n=4)$. The data are expressed as means \pm SE, $* P<0.05$, ** $P<0.01$ as compared with corresponding controls.

tratracheal administration of r-GP sPLA2-II caused a marked decrease in phospholipid content of total crude surfactant (3.9 $\pm 0.7 \mathrm{mg}$ vs. $1.3 \pm 0.4 \mathrm{mg}$ in control and sPLA2-II-treated animals, respectively, $P<0.005 ; n=4)$, associated to an increase in the level of 1-palmitoyl-2-lyso-PC (Fig. $5 B$ ).

These findings led us to investigate the in vitro effect of r-GP sPLA2-II on isolated surfactant. Figure $6 A$ shows that r-GP sPLA2-II $(4 \mu \mathrm{g} / \mathrm{ml})$ was able to hydrolyze surfactant phospholipids, and strikingly, that PC was the preferred substrate for this enzyme. Indeed, generation of lyso-PC by r-GP sPLA2-II was much higher than that of lyso-PG (eight- to tenfold versus twofold increase, respectively). Significant hydrolysis was observed at a concentration of r-GP sPLA2-II as low as $0.1 \mu \mathrm{g} / \mathrm{ml}$ (data not shown). GC/MS analysis of lipid molecular species showed similar pattern than observed during in vivo experiments (Fig. $6 B$ and $C$ ), indicating that DPPC is a major phospholipid substrate for this enzyme.

Analysis of SPLA2-II/SP-A interaction using SPR. We next investigated whether specific surfactant component such as SP-A might be involved in the control of sPLA2-II-mediated surfactant phospholipid hydrolysis. In a first step, using SPR methodology, we analyzed the interaction between r-GP sPLA2-II and purified SP-A. Injection of SP-A $(20 \mu \mathrm{g} / \mathrm{ml})$ in the presence of $\mathrm{Ca}^{2+}(5 \mathrm{mM})$ provides a response curve, reflecting an interaction between r-GP PLA2-II and SP-A, which was not observed in the absence of $\mathrm{Ca}^{2+}$ (Fig. $7 \mathrm{~A}$ ). This interaction was also observed when $\mathrm{Ca}^{2+}$ was replaced by $\mathrm{Mn}^{2+}$ or $\mathrm{Ba}^{2+}$ but not by $\mathrm{Mg}^{2+}$ (Fig. 7 B). No interaction was observed when SP-A was injected in presence of $\mathrm{Ca}^{2+}$ on the sensor chip surface subjected to a blank immobilization, dem-
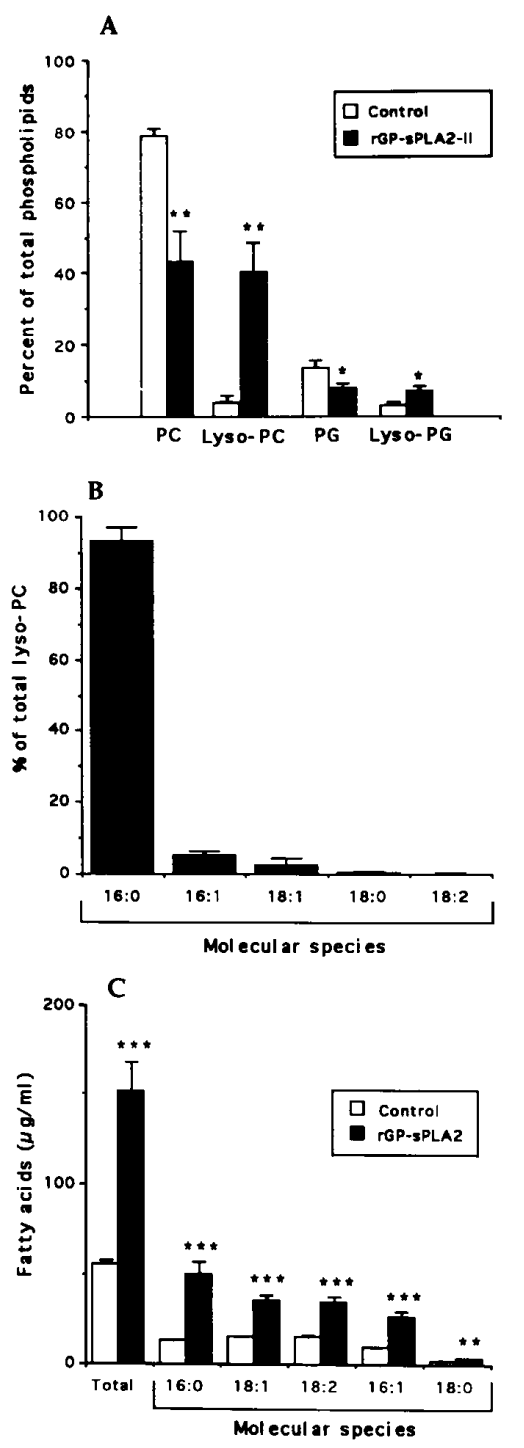

Figure 6. Analysis of in vitro surfactant hydrolysis by recombinant guinea pig sPLA2-II. Surfactant was collected from untreated animals and incubated with 4 $\mu \mathrm{g} / \mathrm{ml}$ of r-GP sPLA2-II as indicated in Methods. (A) shows the effect of r-GP sPLA2-II on the surfactant phospholipid composition (mean $\pm \mathrm{SE}$, $n=5)$; $(B)$ shows the percent distribution of molecular species of the lyso-PC generated by r-GP sPLA2-II (mean \pm SE, $n=5)$; $(C)$ shows the molecular species of the released fatty acids (mean \pm SE, $n=4) . * P<0.05, * * P<$ 0.01 , and ${ }^{* * *} P<0.001$. 

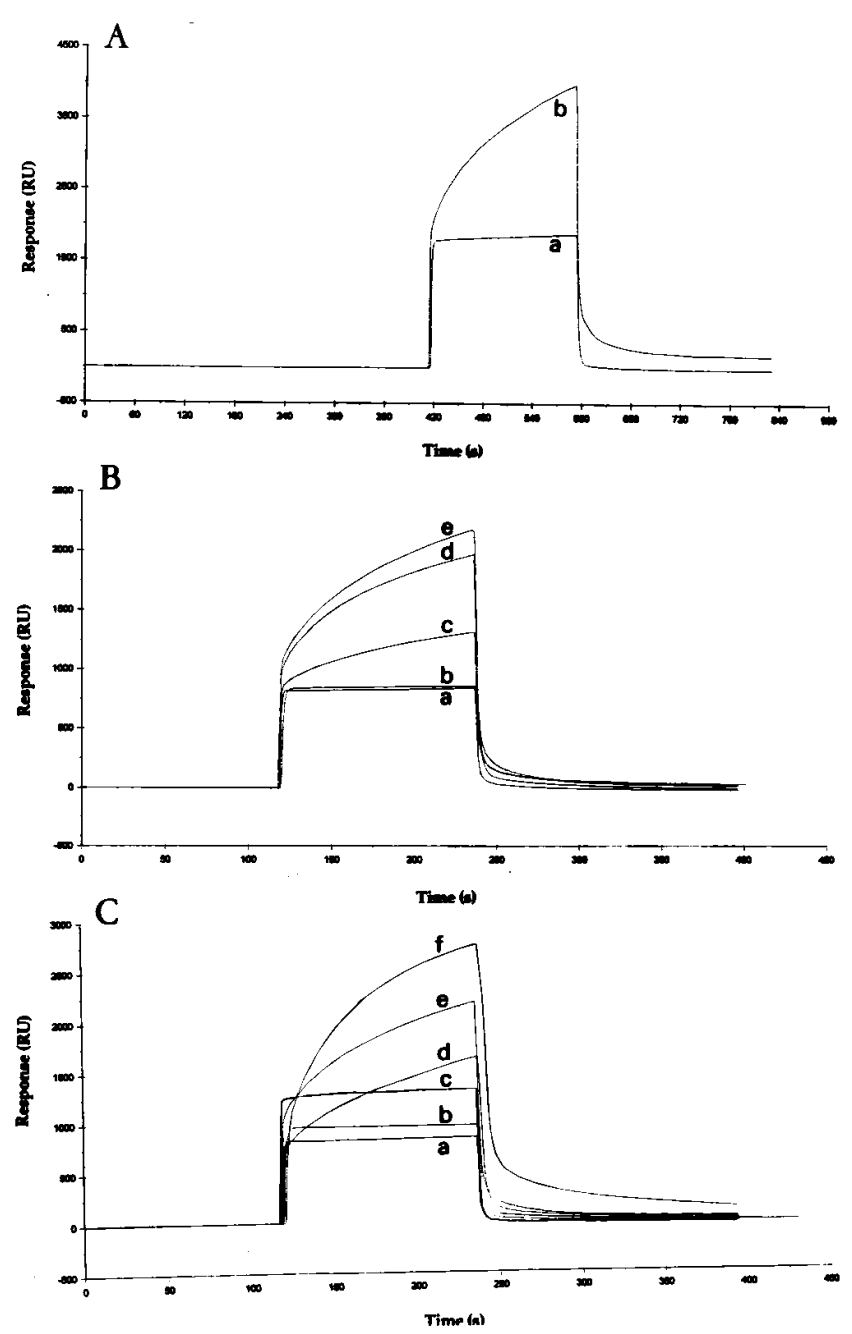

Figure 7. Characterization of sPLA2-II/SP-A interaction using SPR. In $(A), \mathrm{r}$-GP sPLA2-II was immobilized on the dextran matrix as described in Methods. Purified guinea pig SP-A was injected at $25^{\circ} \mathrm{C}$, in a controlled flow of $5 \mathrm{mM}$ Hepes buffer ( $\mathrm{pH}$ 7.4). The progress of SP-A $(20 \mu \mathrm{g} / \mathrm{ml})$ and $\mathrm{r}$-GP sPLA2-II interaction was analyzed in the absence $(a)$ or in the presence $(b)$ of $\mathrm{Ca}^{2+}(5 \mathrm{mM})$. In $(B)$, the divalent cation dependence of SP-A $(10 \mu \mathrm{g} / \mathrm{ml})$ and r-GP sPLA2-II interaction was analyzed. All the experiments were performed at $5 \mathrm{mM}$ cation concentrations; $\mathrm{Mg}^{2+}(b), \mathrm{Mn}^{2+}(c), \mathrm{Ca}^{2+}(d)$, and $\mathrm{Ba}^{2+}(e)$. In (a), SP-A was injected in presence of $\mathrm{Ca}^{2+}$ on the sensor chip surface subjected to a blank immobilization as described in Methods. In $(C)$, the selectivity of SP-A recognition by sPLA2s was analyzed. Naja naja SPLA2-I $(a)$, bee venom sPLA2-III $(b)$, porcine pancreatic SPLA2-I $(c)$, synovial human sPLA2-II $(d)$, r-GP sPLA2-II $(e)$, and crotoxin subunit B $(f)$ were immobilized on the dextran matrix as described in Methods. SP-A $(10 \mu \mathrm{g} / \mathrm{ml})$ was injected in the same buffer in the presence of $\mathrm{Ca}^{2+}(5 \mathrm{mM})$. These data are representative of three separate experiments.

onstrating that SP-A does not show any lectin interaction with the matrix (Fig. 7 B). Pretreatment of SP-A with purified antirat SP-A (at stoichiometric ratio of 1:40) prevented SP-AsPLA2-II interaction (data not shown). Figure $7 C$ shows that SP-A interacts selectively with type II sPLA2s since no signals were observed with Naja naja sPLAL (type I), bee venom sPLA2 (type III), or porcine pancreatic sPLA2 (type I).
Hence, BIAcore analysis shows that SP-A interacts directly with r-GP sPLA2-II through a selective and cation-dependent process.

SPLA2-II/SP-A interaction regulates surfactant phospholipid hydrolysis. The consequences of such interaction on sPLA2-II activity were then investigated. Table I shows a marked decrease of r-GP sPLA2-II activity in the presence of SP-A and depending on the sPLA2-II/SP-A ratio. This effect is not due to substrate depletion since the measurement of sPLA2 activity was carried out in the presence of a 10,000-fold molar excess of phospholipid substrate, compared with SP-A (see Methods). Moreover, PLA2 activity was unaffected when porcine pancreatic sPLA2-I was added instead of r-GP sPLA2-II, indicating that inhibition does not result from an impaired substrate accessibility by SP-A. We next examined the consequence of SP-A/sPLA2-II interaction on surfactant phospholipid hydrolysis. Figure 8 shows that the addition of anti-SP-A antibodies potentiate fatty acid release by $150 \mathrm{ng} / \mathrm{ml}$ r-GP sPLA2-II, therefore remaining above the levels obtained with $300 \mathrm{ng} / \mathrm{ml} \mathrm{r-GP} \mathrm{sPLA2-II.}$

\section{Discussion}

Clinical studies have linked the sPLA2 with lung inflammation, since elevated levels of sPLA2 activity have been reported in ARDS that correlated with the severity of the disease (for review see reference 15). However, no causal relationship has been directly demonstrated. In addition, extrapolation from experimental acute lung injury induced by the intratracheal injection of Naja naja venom (37) is questionable, since venom sPLA2s exhibit a much higher ability than mammalian sPLA2-II to hydrolyze phospholipids on packed monolayer structures $(38,39)$. Hence, the ability of mammalian sPLA2-II to generate lipid derivatives in acute lung injury has remained unknown.

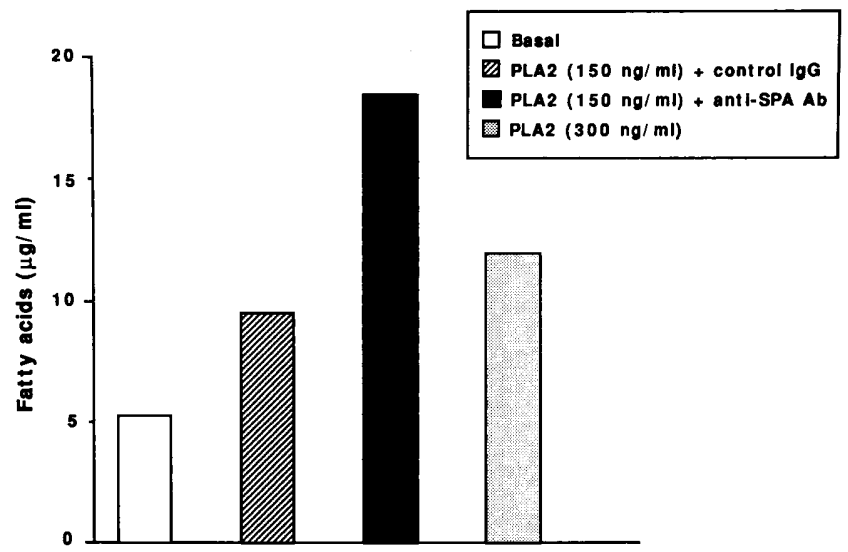

Figure 8. Consequence of sPLA2-II/SP-A interaction on fatty acid release. $4 \mathrm{mM}$ of surfactant phospholipid $(600 \mu \mathrm{g} / \mathrm{ml}$ total proteins) were preincubated in a 50- $\mu$ l volume containing anti-rat IgG SP-A $(5.2 \mu \mathrm{g})$ or control IgG overnight at room temperature. Next, surfactant was incubated for $2 \mathrm{~h}$ at $37^{\circ} \mathrm{C}$ with indicated concentrations of r-GP sPLA2-II. The results show the release of fatty acids in basal conditions, in the presence of $150 \mathrm{ng} / \mathrm{ml}$ of sPLA2-II and anti-SP-A $\mathrm{IgG}$, or control IgG, and in the presence of $300 \mathrm{ng} / \mathrm{ml}$ of sPLA2-II alone. The data are representative of two separate experiments carried out in triplicate. 
The present investigation clearly identifies sPLA2-II as a crucial enzyme involved in the in vivo generation of lyso-PC and fatty acids in the lung. Using two different sets of in vivo experiments, we found that both endogenous sPLA2-II, produced after LPS administration, and exogenous r-GP sPLA2II, administered intratracheally, generated lipid derivatives in the alveolar space. We show that surfactant phospholipids are a major target of this enzyme. Indeed, 1-palmitoyl-2-lyso-PC and palmitic acid were the main lipid derivatives released in the BALF during LPS or rGP sPLA2-II challenges. This was accompanied by a dramatic decrease of the phospholipid content and a parallel increase in the level of lyso-PC in crude surfactant. However, our results show that the lavage levels of arachidonic acid were extremely low when compared with those of other fatty acids. This may be explained by the fact that the pulmonary surfactant is the first target of sPLA2-II, at least at the early stage of acute lung injury. Indeed, the content of arachidonic acid in surfactant phospholipids is extremely low in guinea pig (data not shown) as in other animal species (36).

The susceptibility of surfactant phospholipids to hydrolysis by sPLA2-II is in agreement with the fact that the alveolar macrophage, the major cell source of this enzyme during LPSinduced acute lung injury (25), is in direct contact with pulmonary surfactant. Since the catalytic activity of sPLA2-II requires millimolar calcium concentrations (13), which are reached in the alveolar space $(40,41)$, this enzyme may become fully active once released by AM in the extracellular space. Remarkably, surfactant alterations were observed $2 \mathrm{~h}$ after the r-GP sPLA2-II administration, indicating that the enzyme could account for surfactant abnormalities that occur early in the course of ARDS (2). The lyso-PC resulting from surfactant phospholipid hydrolysis may play an important role in the development of acute lung injury. Indeed, intratracheal administration of lyso-PC to hamster has been shown to increase vascular premeability and to alter intensively the alveolo-capillary membrane (3).

The ability of a mammalian sPLA2-II to hydrolyze surfactant PC was unexpected, since in contrast to venom sPLA2s, this enzyme was reported to act poorly on PC substrate and to exhibit a headgroup preference for negatively charged phospholipids such as phosphatidylglycerol $(39,42)$, which is unusually abundant in pulmonary surfactant as compared with other mammalian tissues and fluids (43). However, local conditions that increase substrate accessibility can influence sPLA2 activity, allowing for a better penetration into the interface. Indeed, on a monolayer PC substrate, the surface pressure or packing density of phospholipid molecules modulates mammalian sPLA2 activity (39). Thus, one can conclude from these data that the physicochemical organization of phospholipids is an important determinant of their hydrolysis by sPLA2. In our study, the incubation of surfactant with sPLA2II was performed at $37^{\circ} \mathrm{C}$, which is in the range of the gel to liquid crystal transition or melting temperature $\left(T_{\mathrm{m}}\right)$ of whole phospholipid surfactant in mammals (44). Then, the surfactant monolayer phase becomes heterogenous, associating a gel and liquid state. Indeed, the $T_{\mathrm{m}}$ of DPPC is $41^{\circ} \mathrm{C}$, but, in the presence of phosphatidylglycerol and unsaturated lipids, the apparent $T_{\mathrm{m}}$ of the lipid mixture is shifted down to $37^{\circ} \mathrm{C}(45,46)$. On artificial phospholipid substrates, this microheterogeneity was reported to enhance greatly the interfacial recognition with sPLA2, therefore increasing the catalytic activity (47).
Hence, the thermotropic phase change of DPPC induced by the presence of non-DPPC phospholipid within surfactant may be an important factor rendering DPPC more susceptible to hydrolysis by SPLA2.

Our findings also demonstrate that hydrolysis of surfactant phospholipids is regulated by a protein-protein interaction between SP-A and sPLA2-II. Indeed, SPR analysis reveals a direct, selective, and calcium-dependent interaction between SP-A and sPLA2-II. This result is in line with previous studies which showed that calcium plays an essential role in the interaction of SP-A with carbohydrate ligands (48) and with a high-affinity receptor expressed on alveolar type II cells (49). Preincubation of SP-A with r-GP sPLA2-II in the presence of $\mathrm{Ca}^{2+}$ markedly reduced $r-G P$ sPLA2-II activity. In contrast, no inhibition was observed with pancreatic porcine sPLA2-I. Furthermore, incubations were performed with an excess of phospholipid substrate, indicating that the inhibition of r-GP sPLA2-II activity was not due to an impairment of substrate accessibility. Taken together, these data indicate that, in contrast to annexins (50), SP-A does not alter sPLA2-II activity by sequestering phospholipid substrates but, as shown by BIAcore analysis, through a direct protein-protein interaction. The high selectivity of SP-A interaction with sPLA2s-II may indicate that the catalytic site of the enzyme is not directly involved, since amino acid residues of the catalytic domain of sPLA2s are highly conserved among all secretory PLA2s types (51). However, the CRD of SP-A shares sequence homology with venom sPLA2 inhibitors purified from the plasma of the Habu snake T. flavoridis sPLA2-II (18). Site-directed mutagenesis will be required to determine whether CRD sequence of SP-A is involved in SPLA2-II recognition.

We investigated the physiological relevance of sPLA2-II/ SP-A interaction by examining its consequence on surfactant phospholipid hydrolysis. We show that this interaction inhibits in situ surfactant phospholipid hydrolysis. The inhibitory role of SP-A is particularly important to consider in the light of clinical studies which reported a pronounced decrease of SP-A concentration in ARDS patients $(1,2)$. Thus, a marked defect in alveolar SP-A may promote the excessive catabolism of surfactant phospholipids by sPLA2-II during ARDS. As a consequence, the lack of SP-A in synthetic surfactant may partially account for its failure to improve survival of ARDS patients (52).

In conclusion, our study clearly identifies for the first time the in vivo involvement of mammalian sPLA2-II in the acute generation of proinflammatory lipid mediators in lung, mainly resulting from the hydrolysis of surfactant phospholipids. DPPC, the main component responsible for the surface tension reducing property of the surfactant complex, is the preferred target for this enzyme. We propose that SP-A plays an important role in vivo in the regulation of surfactant hydrolysis by acting as a specific inhibitor of sPLA2-II and that the balance between these two proteins may have a critical importance in the development of ARDS.

\section{Acknowledgments}

We gratefully acknowledge Dr. Edward Mihelich for providing us the sPLA2-II inhibitor LY 311727.

L. Arbibe was supported by the Caisse Nationale d'Assurance des Professions Indépendantes and Pasteur-Weizmann. 


\section{References}

1. Lewis, J.F., and A.H. Jober. 1993. Surfactant and Adult Respiratory Distress Syndrome. Am. Rev. Respir. Dis. 147:218-233.

2. Gregory, T.J., W.J. Longmore, M.A. Moxley, J.A. Whitsett, C.R. Reed, A.A. Fowler, L.D. Hudson, R.J. Maunder, C. Courtney, and T.M. Hyers. 1991. Surfactant chemical composition and biophysical activity in Acute Respiratory Distress Syndrome. J. Clin. Invest. 88:1976-1981.

3. Niewoehner, D.E., K. Rice, A.A. Sinha, and D. Wangensteen. 1987. Injurious effects of lysophatidylcholine on barrier properties of alveolar epithelium. J. Appl. Physiol. 63:1979-1986.

4. Lindhal, M., A.R. Hede, and C. Tagesson. 1986. Lysophosphatidylcholine increases airway and capillary permeability in the isolated perfused rat lung. Exp. Lung Res. 11:1-12.

5. Holm, B.A., L. Keicher, M. Liu, J. Sokolowski, and G. Enhorning. 1991. Inhibition of pulmonary surfactant by phospholipases. J. Appl. Physiol. 71:317-321.

6. Sasaki, Y., Y. Asaoka, and Y. Nishizuka. 1993. Potentiation of diacylglycerol-induced activation of protein kinase $\mathrm{C}$ by lysophospholipids. Subspecies difference. FEBS Lett. 320:47-51.

7. Asaoka, Y., M. Oka, N. Yoshida, and Y. Nishizuka. 1991. Lysophosphatidylcholine as possible second messenger synergistic to diacylglycerol and calcium ion for T-lymphocyte activation. Biochem. Biophys. Res. Commun. 178: $1378-1385$.

8. Hoffman, R.D., M. Kligerman, T.M. Sundt, N.D. Anderson, and H.S. Shin. 1982. Stereospecific chemoattractant of lymphoblastic cells by gradients of lysophosphatidylcholine. Proc. Natl. Acad. Sci. USA. 79:3285-3289.

9. Ryborg, A.K., B. Deleuran, K. Thertrup-Pedersen, and K. Kragballe. 1994. Lysophosphatidylcholine: a chemoattractant to human T lymphocytes. Arch. Dermatol. Res. 286:462-465.

10. Quinn, M.T., S. Parthasarathy, and D. Steinberg. 1988. Lysophosphatidylcholine: a chemotactic factor for human monocytes and its potential role in atherogenesis. Proc. Natl. Acad. Sci. USA. 85:2805-2809.

11. Kume, N.K., M.I. Cybulsky, and M.A. Gimbrone. 1992. Lysophosphatidylcholine, a component of atherogenic lipoprotein, induces mononuclear leukocyte adhesion molecules in cultured human and rabbit arterial endothelial cells. J. Clin. Invest. 90:1138-1144.

12. Yokote, K., N. Morisaki, M. Zenibayashi, S. Ueda, T. Kanzaki, Y. Saito, and S. Yoshida. 1993. The phospholipase-A2 reaction leads to increased monocyte adhesion of endothelial cells via the expression of adhesion molecules. Eur. J. Biochem. 217:723-729.

13. Dennis, E.A. 1997. The growing phospholipase A2 superfamily of signal transduction enzymes. Trends Biochem. Sci. 22:1-2.

14. Chilton, F.H., F.J. Averill, W.C. Hubbard, A.N. Fonteh, M. Triggiani, and M.C. Liu. 1996. Antigen-induced generation of lyso-phospholipids in human airways. J. Exp. Med. 183:2235-2245.

15. Arbibe, A., D. Vial, and L. Touqui. 1997. Phospholipase A2 and acute respiratory distress syndrome. Prog. Surg., 24:79-87.

16. Kuroki, Y., and D.R. Voelker. 1994. Pulmonary surfactant proteins. $J$. Biol. Chem. 269:25943-25946.

17. Kogaki, H., S. Inoue, K. Ikeda, Y. Samejima, T. Omotori-Satoh, and K. Hamaguchi. 1989. Isolation and fundamental properties of a phospholipase A2 inhibitor from the blood plasma of Trimeresurus flavoridis. J. Biochem. 106: 966-971.

18. Inoue, S., H. Kogaki, K. Ikeda, Y. Samejima, and T. Omotori-Satoh. 1991. Amino acid sequences of the two subunits of a phospholipase A2 inhibitor from the blood plasma of Trimeresurus flavoridis. Sequence homologies with pulmonary surfactant apoprotein and animal lectins. J. Biol. Chem. 266: 1001-1007.

19. Smith, G.E., G. Ju, B.L. Ericson, J. Moschera, H.W. Lahm, R. Chizzonite, and M.D. Summers. 1985. Modification and secretion of human interleukin 2 produced in insect cells by a baculovirus expression vector. Proc. Natl. Acad. Sci. USA. 82:8404-8408.

20. Longacre, S., K.N. Mendis, and P.H. David. 1994. Plasmodium vivax merozoite surface protein 1C-terminal recombinant proteins in baculovirus. Biol. Biochem. Parasitol. 64:191-205.

21. Schägger, H., and G. Von Jagow. 1987. Tricine-sodium dodecyl sulfate polyacrylamide-gel electrophoresis for the separation of proteins in the range from 1 to $100 \mathrm{kDa}$. Anal. Biochem. 166:368-379.

22. Katyal, S.L., L.W. Estes, and B. Lombardi. 1977. Method for the isolation of surfactant from homogenates and lavages of lung of adult, newborn, and fetal rats. Lab. Invest. 36:585-592.

23. Kuroki, Y., R.J. Mason, and D.R. Voelker. 1988. Pulmonary surfactant apoprotein A structure and modulation of surfactant secretion by rat alveolar type II cells. J. Biol. Chem. 263:3388-3394.

24. Böttcher, C.J.F., C.M. van Gent, and C. Pries. 1961. A rapid and sensitive sub-microphosphorus determination. Anal. Clin. Acta. 24:203-204.

25. Arbibe, L., D. Vial, I. Rosinski-Chupin, N. Havet, M. Huerre, B.B. Vargaftig, and L. Touqui. 1997. Endotoxin induces expression of phospholipase A2 during acute lung injury in guinea pigs. J. Immunol. 159:391-400.

26. Schevitz, R.W., N.J. Bach, D.G. Carlson, N.Y. Chirgadze, D.K. Clawson, R.D. Dillard, S.E. Draheim, L.W. Hartley, N.D. Jones, E.D. Mihelich, et al. 1995. Structure-based design of the first potent and selective inhibitor of human non-pancreatic secretory phospholipase A2. Nat. Struct. Biol. 2:458-465.

27. Filgueiras, O.M.O., and F. Possmayer. 1987. Characterization of phospholipase A2 from rabbit lung microsomes. Lipids. 22:731-735.

28. Bligh, E.G., and W.J. Dyer. 1959. A rapid method of total lipid extraction and purification. Can. J. Biochem. Physiol. 37:911-918.

29. Tsujishita, Y., Y. Asaoka, and Y. Nishizuka. 1994. Regulation of phospholipase A2 in human leukemia cell lines: its implication for intracellular signalling. Proc. Natl. Acad. Sci. USA. 91:6274-6278.

30. Gregory, D.W., and M.A. Williams. 1967. The preparation of ferritin labelled antibodies and other protein-protein conjugates with bis-diazotized benzidine. Biochim. Biophys. Acta. 133:319-332.

31. Vial, D., M. Senorale-Pose, N. Havet, L. Molio, B.B. Vargaftig, and L. Touqui. 1995. Expression of the type-II PLA2 in alveolar macrophages: downregulation by an inflammatory signal. J. Biol. Chem. 270:17327-17332.

32. Szabo, A., L. Stolz, and R. Gransow. 1995. Surface plasmon resonance and its use in biomolecular interaction analysis (BIA). Curr. Opin. Struct. Biol. 5:699-670.

33. Faure, G., J.L. Guillaume, L. Camoin, B. Saliou, and C. Bon. 1991. Multiplicity of acidic subunit isoforms of crotoxin, the phospholipase A2 neurotoxin from Crotalus durrissus terrificus venom, results from posttranslational modifications. Biochemistry. 30:8074-8083.

34. Haagsman, H.P., R.T. White, J. Schilling, K. Lau, B.J. Benson, J. Golden, S. Hawgood, and J.A. Clements. 1989. Studies of the structure of lung surfactant protein SP-A. Am. J. Physiol. (Lung. Cell. Mol. Physiol). 257:L421L429.

35. Radvanyi, F., L. Jordan, F. Russo-Marie, and C. Bon. 1989. A sensitive and continuous fluorometric assay for phospholipase A2 using pyrene-labelled phospholipid in the presence of serum albumin. Anal. Biochem. 177:103-109.

36. Shelley S.A., J.E. Paciga, and V. Balis. 1984. Lung surfactant phospholipids in different animal species. Lipids. 19:857-862.

37. Edelson, J.D., P. Vadas, J. Villar, J.B.M. Mullen, and W. Pruzanski. 1991. Acute lung injury induced by phospholipase A2. Am. Rev. Respir. Dis. 143:1102-1109.

38. Verheij, H.M., M.C. Boffa, C. Rothen, M.C. Bryckaert, R. Verger, and V. de Haas. 1980. Correlation of enzymatic activity and anticoagulant properties of phospholipase A2. Eur. J. Biochem. 112:25-32.

39. Ransac, S., A.J. Aarsman, H. van den Bosch, C. Gancet, G.H. de Haas, and R. Verger. 1992. Rat platelet phospholipase A2. Kinetic characterization using the monomolecular film technique. Eur. J. Biochem. 204:793-797.

40. Nielson, D.W. 1986. Electrolyte composition of pulmonary alveolar subphase in anesthetized rabbits. J. Appl. Physiol. 60:972-979.

41. Nielson, D.W., and M.B. Lewis. 1988. Calcium increases in pulmonary alveolar fluid in lambs at birth. Pediatr. Res. 24:322-325.

42. Snitko, Y., E.T. Yoon, and W. Cho. 1997. High specificity of human secretory class II phospholipase A2 for phosphatidic acid. Biochem. J. 321:737-741.

43. Rooney, S.A. 1985. The surfactant system and lung phospholipid biochemistry. Am. Rev. Respir. Dis. 131:439-460.

44. McMurchie, E.J., J.K. Teubner, and R.A. Gibson. 1983. Thermal phase transition in sheep, rat and rabbit surfactant lipids detected by differential scanning calorimetry. Comp. Biochem. Physiol. 74A:295-299.

45. Egberts, J., H. Sloot, and A. Mazure. 1989. Minimal surface tension, squeeze-out and transition temperatures of binary mixtures of dipalmitoylphosphatidylcholine and unsaturated phospholipids. Biochim. Biophys. Acta. 1002: 109-113.

46. Keough, K.M. 1992. Physical chemistry of pulmonary surfactant in the terminal air spaces. In Pulmonary Surfactant: From Molecular Biology to Clinical Practice. L.M.G. van Golde and J.J. Batenburg, editors. Elsevier Science Publishers, Amsterdam. 109-164.

47. Honger, H., K. Jorgensen, R.L. Biltonen, and O.G. Mouritsen. 1996. Systematic relationship between phospholipase A2 activity and dynamic lipid bilayer microheterogeneity. Biochemistry. 35:9003-9006.

48. Haagsman, H.P., S. Hawgood, T. Sargeant, D. Buckley, R.T. White, K. Drickamer, and B.J. Benson. 1987. The major lung surfactant protein, SP-28-36, is a calcium-dependent carbohydrate-binding protein. J. Biol. Chem. 262: $13877-13880$.

49. Kuroki, Y., R.J. Mason, and D.R. Voelker. 1988. Alveolar type II cells express a high affinity for pulmonary surfactant. Proc. Natl. Acad. Sci. USA. 85: $5566-5570$.

50. Davidson, F.F., E.A. Dennis, M. Powell, and J.R. Glenney. 1987. Inhibition of phospholipase A2 by "lipocortines" and calpactins. An effect of binding to substrate phospholipids. J. Biol. Chem. 262:1698-1705.

51. Wery, J.P., R.W. Shevitz, D.K. Clawson, J.L. Bobbitt, E.R. Dow, G. Gamboa, T. Goodson, R.B. Hermann, R.M. Kramer, D.B. McClure, et al. 1991. Structure of recombinant human synovial fluid phospholipase A2 at 2.2 A resolution. Nature 352:79-82.

52. Anzueto, A., R.P. Baughman, K.K. Guntupalli, J.G. Weg, H.P. Wiedmann, A.A. Raventos, F. Lemaire, W. Long, D.S. Zaccardelli, and E.N. Pattishall. 1996. Aerosolized surfactant in adults with sepsis-induced Acute Respiratory Distress Syndrome. Exosurf Acute Respiratory Distress Syndrome Sepsis Study Group. N. Engl. J. Med. 344:1417-1421. 